\title{
GEMSTONE DURABILITY: DESIGN TO DISPLAY
}

\author{
By Deborah Dupont Martin
}

Knowledge of the durability of a gemstone is critical to understanding the risks involved in the various setting, repair, and cleaning procedures commonly used by the jeweler. Some gemstones need attention in display because of their reaction to heat and/or light. This article reviews gemstone durability considerations for 31 species and their varieties as they affect design decisions as well as repair, cleaning, and display of the piece. In all cases, the reader is advised to consult an experienced bench jeweler before attempting any potentially damaging procedures. The recommendations in this article are offered from a gemological viewpoint and as guidelines only.

\section{ABOUT THE AUTHOR}

Ms. Martin is an instructor in the Colored Stones Department of the Resident Gemology Program at the Gemological institute of America, Santa Monica, California. Prior to joining G/A, she worked as a bench jeweler for 10 years.

Acknowledgments: The following people were extremefy hefoful in reviewing the manuscript and providing information: Thornton Mann, Chuck Almore, Dino DeGhionno, and Archie Curtis. Robert Kane was especially helpful in providing information for the chart and photographs. Thanks to Chris Keenan for supplying photographs. Special thanks to Sleven C. Martin for providing many insights and useful information, as well as encouragement. The following graciously supplied jewelry for photographs: The Altobelli Jewelers, The Gold Masters, Silverhorn. Steven C. Martin, and C. Y. Sheng. Puth Patchick did a wonderful job typing the manuscript.

(a) 1987 Gemological Institute of America
Tn today's market, most jewelers no longer deal solely 1 with traditional gems such as diamonds, rubies, sapphires, and pearls. The increasing availability and popularity of a wide range of colored stones-tanzanite, tsavorite, iolite, and tourmaline (figure 1), to name a few has opened a host of new possibilities in jewelry, but it has also added a multitude" of new risks.

While many in the trade are qualified to deal effectively with most of these stones, virtually everyone associated with the design, manufacture, and sale of jewelry should be aware of the potential problems of a particular gem material. The designer must know which mounting will protect the stone best while still enhancing its natural beauty. The bench jeweler is responsible for determining what stones are at risk in which setting or repair procedures. The salesperson, who has the greatest customer contact, must not only be aware of these design and bench considerations, but must also know the rules involved in various cleaning procedures and be able to advise the customer regarding precautions in care and wear. Some stones even require special display considerations because they are sensitive to light or to the heat that can be produced in a case.

The most important factor in designing, setting, repairing, or cleaning a piece of jewelry is durability. Essentially, durability is the gemstone's ability to resist scratching (hardness), breaking (toughness), and effects caused by heat, light, or chemicals (stability). The present article examines gemstone durability and discusses the limitations and advantages of different settings, repair and cleaning procedures, and display practices for many different stones. A chart is included to provide guidelines relating to durability and how it affects these procedures for 31 gem species and their varieties.

It is important to note that the following information pertains to natural gems only, including common enhan- 
cements, but not to any man-made materials. The identity of a gem must be established before any procedure beyond cleaning with warm soapy water may be attempted. If you cannot determine with certainty whether or not a stone has been enhanced, assume that it has and take the more conservative approach. Many qualified bench jewelers will be able to perform procedures that are not recommended here, but such an individual is not always available. This article, therefore, is intended to serve as guidelines (and guidelines only) in these areas. Since there is some risk involved with any stone, consultation with a qualified bench jeweler is always recommended.

The information in this article was compiled based on Webster (1983), Sinkankas (1972), Palache et al. (1944), Nassau (1984), and the GIA course materials, as well as on the experience of the author and her communications with colleagues in both gemology and jewelry manufacturing. A glossary is included to define some of the more technical terms.

\section{DESIGNING AND MANUFACTURING FOR GEMSTONE SAFETY AND WEARABILITY}

Durability determines the safest way a stone may be set and worn. Stones that are very resistant to most types of setting, cleaning, and repair procedures (e.g., diamond and corundum) may be used in a wide variety of jewelry designs. For stones of lesser durability, however, possible weaknesses must be considered in the selection of a setting style (see chart). A gem with poor toughness, such as topaz, would not be a candidate for a channel or flush style setting; chances are the stone would break. Heat-sensitive stones such as emerald, tsavorite, and tanzanite could be subject to damage if set in a style that requires soldering near stones already in place.

Some inclusions can increase the chance of breakage during setting. Because such inclusions vary from stone to stone, it is wise to examine the stone under magnification before setting it. Fractures or inclusions near the girdle edge, in particular, contribute to the fragility of a stone, as does possible cleavage (e.g., topaz and kunzite). In addition, a number of manufacturing jewelers have reported to the author that some enhancements (such as heating corundum, tanzanite, or blue zircon) may cause brittleness, which results in a gem that is more easily chipped and abraded.

Unusual and "problem" cuts create special design problems. Many stones are asymmetrical or are cut with very deep pavilions, and thus require a special mounting. Other stones have extremely

\section{GLOSSARY}

Beads: Small portions of metal raised with a graver from the background metal for the purpose of holding a stone in place or for decoration.

Bright-cut: An incised accent cut made with a flat graver that both cuts and polishes metal at the same time.

Burnisher: A highly polished oval-shaped steel blade that is used to smooth metal.

Burr: A small cutting tool, available in various shapes and sizes, that is inserted into a flexshaft and used to excavate, shape, and cut metal during the setting process.

Chasing hammer: A lightweight, well-balanced hammer that is used in conjunction with a setting punch to work metal, e.g., to push a bezel onto the stone and, with various other hand tools, to create raised and indented decorative patterns.

Flexshaft: A machine that consists of a handpiece to hold burrs and other small rotating tools, connected to a flexible shaft approximately 36 inches $(91 \mathrm{~cm})$ in length that attaches to a motor. A foot pedal controls the power.

Flux: A solution (usually a commercial preparation containing borax) used to promote the flow of solder and prevent oxidation in the area.

Graver: A sharp tool used to cut and shape metal. Several different sizes and shapes are commonly used for different types of settings.

Reciprocating hammer: An automatic hammer attachment used in conjunction with the flexshaft in some setting techniques.

Setting punch: A small rod used with a chasing hammer to secure bezels. May be used for channel and flush setting also.

Vector technique: A lateral back-and-forth movement of opposite adjacent pairs of prongs. 


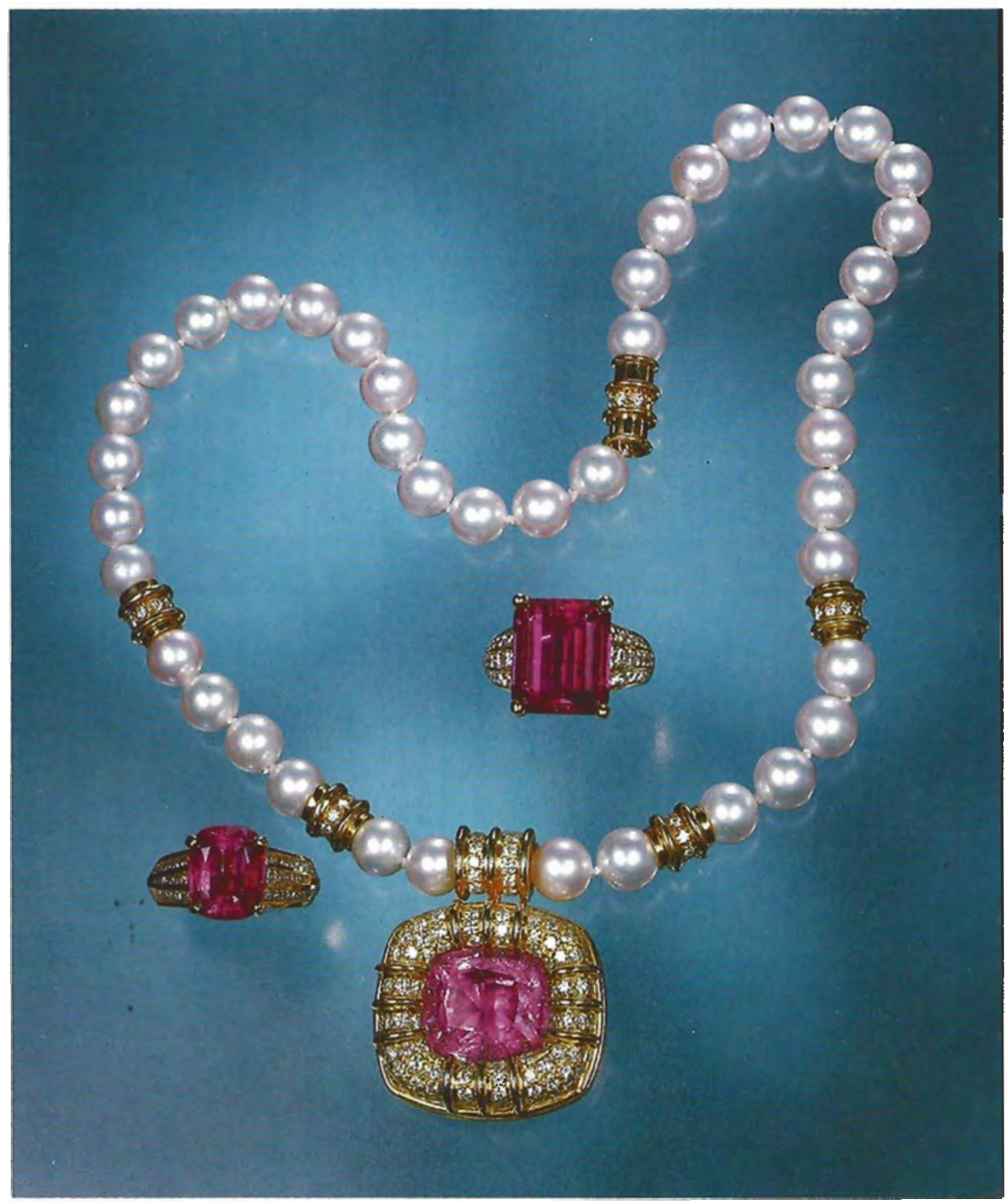

Figure 1. Tourmaline is one of the most popular of the "new" colored gems in the marketplace. This pendant (18.83 ct) and the two rings (5.54 and $13.50 \mathrm{ct}$ ) are all prong set. Jewelry courtesy of The Collector, La Jolla and Fallbrook, CA; photo (c) Harold e) Erica Van Pelt.

thin girdles, or have sharp points that should be protected; for these stones, a setting must be designed that will protect the girdle or points without causing damage during manufacturing. Extra care must be taken with stones that are both unusually cut and that do not withstand setting procedures well.

How the item will be worn is another factor. Many fragile gems, such as topaz, bicolored tourmaline, tanzanite, kunzite, and pearls, are best set in pendants, earrings, brooches, tie tacks, or in rings designed for occasional wear. Cuff links and bracelets are better suited for stones that are more resistant to abrasion and chipping, such as diamond, corundum, jadeite, and chalcedony. Because the table area of a gemstone is very difficult to protect, it is best to choose a more durable stone for a ring, which is subject to much harder wear than any other type of jewelry. If the customer insists that you put a fragile stone in a ring that will be worn with some frequency, try protecting it with creative forms of metalwork rising above the table, or select a setting style such as bezel that will minimize the risk.

There are two principal ways to design jewelry: (1) design a piece and then find stones to fit the design /commonly done when producing many pieces from one design, and requires that the stones used be readily available in calibrated sizes), and $(2)$ custom create a piece of jewelry to display a specific stone (the method preferred for fragile or unusually cut gemstones). Both types of design require the use of one or more setting procedures, each of which - as described below - has its own 
Gemological Guidelines for Gemstone Durability in Jewelrya

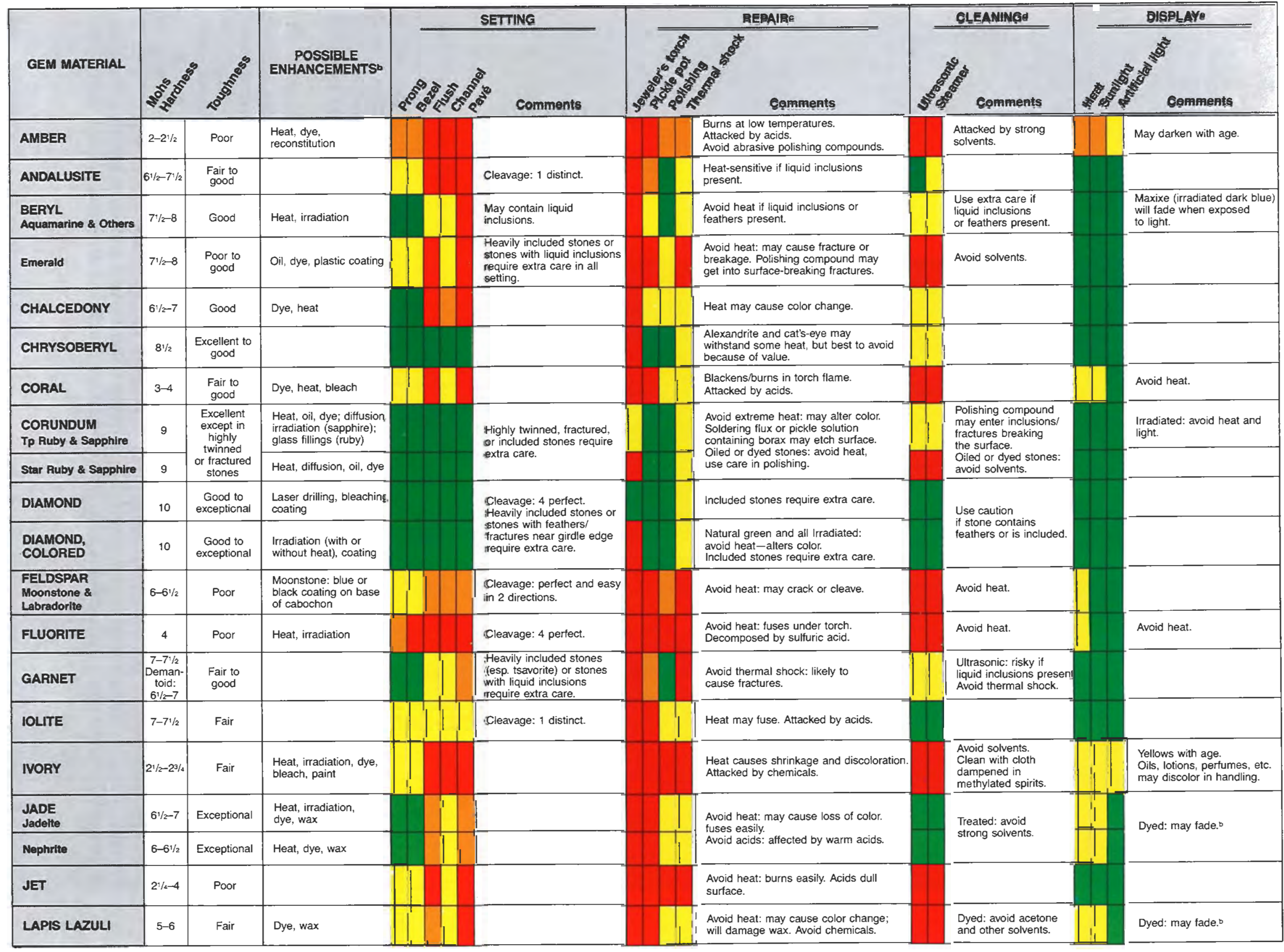




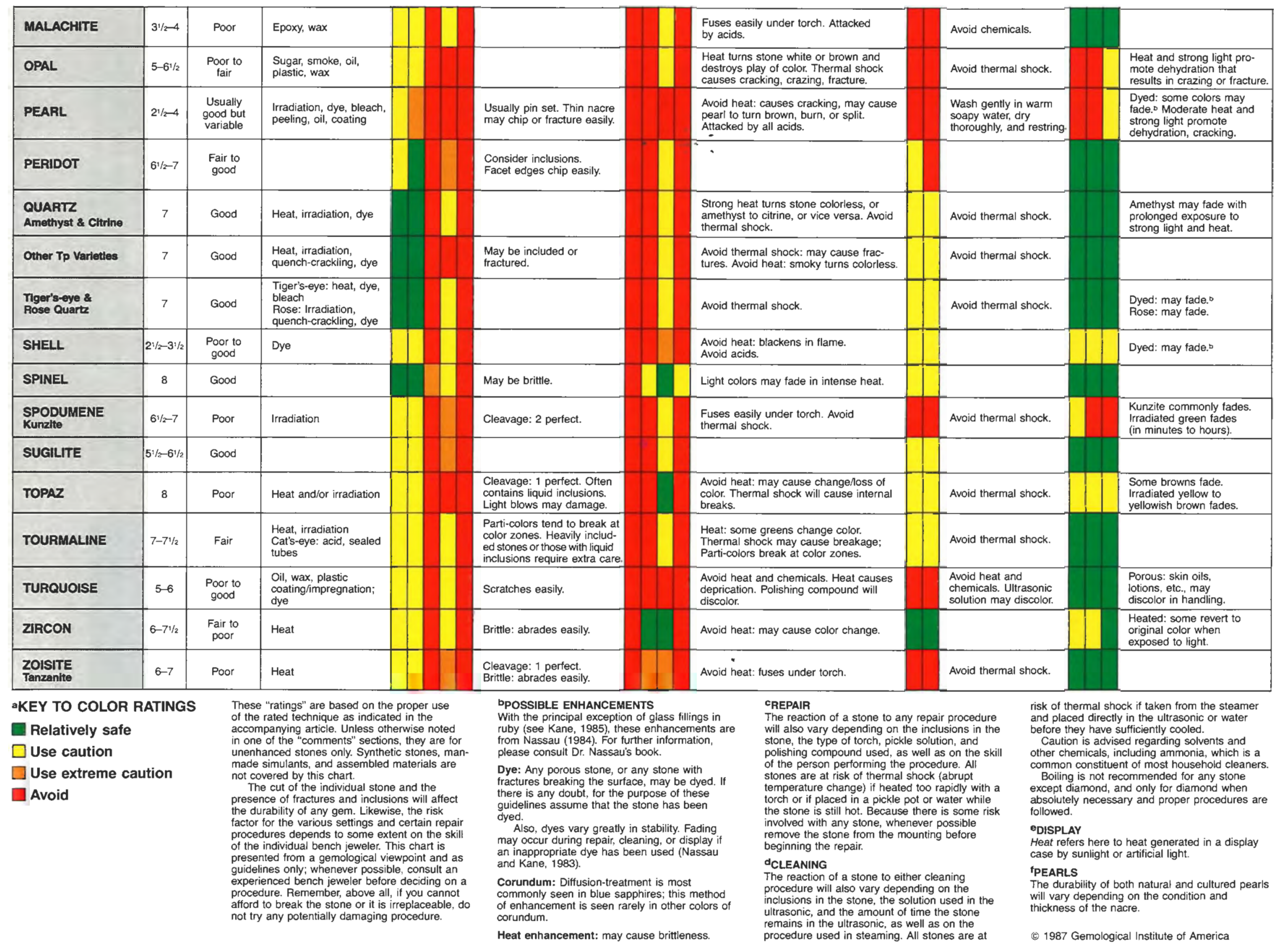


advantages and disadvantages with regard to displaying the stone and protecting it both during the setting procedure and subsequent wear.

Again, an extremely skilled setter may be able to perform any of these setting techniques on any given stone. If such a setter is available, the possibilities are virtually unlimited. The following guidelines, however, are provided to help those who do not have manufacturing experience or the setter who has not worked with some of these stones. Ultimately, the skill of the setter will determine whether a certain setting style can be used for a particular stone.

Prong Setting. This is probably the most common type of setting. It can be used in virtually any type of jewelry for setting almost any cut of stone (again, see figure 1). Some stones, however, require more care than others (see chart).

Prong setting involves placing a stone in either a head or basket mounting, which may be premade or custom fabricated to fit the specific stone. A "head" is usually diestruck and made to fit any stone of a standard calibrated size. A basket is more often cast or fabricated from wire to fit a particular stone. There may be any number of prongs, depending on the size and shape of the stone, and the mounting style.

When deciding whether or not to use a prong setting, consider whether the stone can withstand the pressure caused by the prongs being bent over the girdle edge onto the crown and then tightened into place. Even diamond may sustain damage if a setter is heavy handed when bending a prong over the crown (figure 2). If the stone has an extremely thin girdle, is fractured, or cleaves easily, an

Figure 2. Excessive pressure applied during prong setting may damage any stone, even diamond, as shown by the stress feather seen here. Photo (C Tino Hammid.

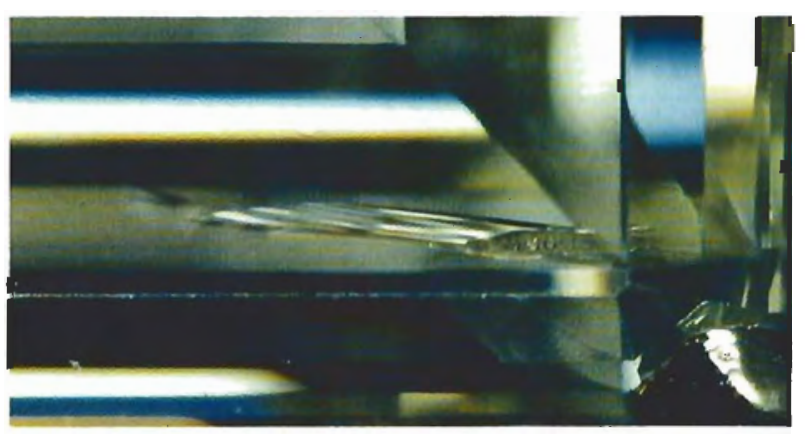

alternative method would be first to cut and fit the seat (the area where the stone rests on the prongs) to an inexpensive synthetic stone of the same proportions. After the prongs have been shaped, slip the fragile stone into place and tighten the prongs by vector technique.

Although prong setting can be performed on almost any stone, it does not offer as much protection as other setting styles. When designing for a stone that chips, abrades, or cleaves easily (e.g., emerald, tanzanite, kunzite) consider a setting style that covers the girdle area to maximize the wearability of the piece.

Bezel Setting. This is an excellent way to protect the girdle and pavilion areas of many gemstones (figure 3). It is effective used alone or in combination with other setting styles.

A bezel is a rim of metal that is soldered onto a mounting. The bezel is first shaped to fit around the girdle of the stone being set before it is soldered in place. Procedures for setting the stone differ slightly depending on whether the stone is faceted or cabochon cut, and, if cabochon cut, whether an open- or closed-back setting is being used. Cast bezels are also available, but they are not as pliable and, therefore, are harder to work with and expose the stone to greater risk.

Although bezel setting has been used most commonly on cabochon-cut stones, it is now being used with greater frequency on faceted stones. The primary advantage with this type of setting is that the band of metal surrounding the girdle of the stone offers protection, yet is thin enough to be burnished over the stone without causing damage if care is exercised in the procedure. A bezel can be especially effective with unusual cuts. The thin line of metal encircling the stone leads the eye to and around the gem, creating a focal point in the design.

A related procedure, tube setting, has gained popularity in recent years (again, see figure 3). A tapered or straight tube, rather than a rim, is used for this style. Because the metal for a tube setting is usually thicker than that of a bezel, more pressure is required in burnishing and this technique is recommended only for diamond or corundum.

Flush Setting. This type of setting creates a very smooth, tailored look (figure 4) and is a popular style for men's rings. The stones are set low and the 


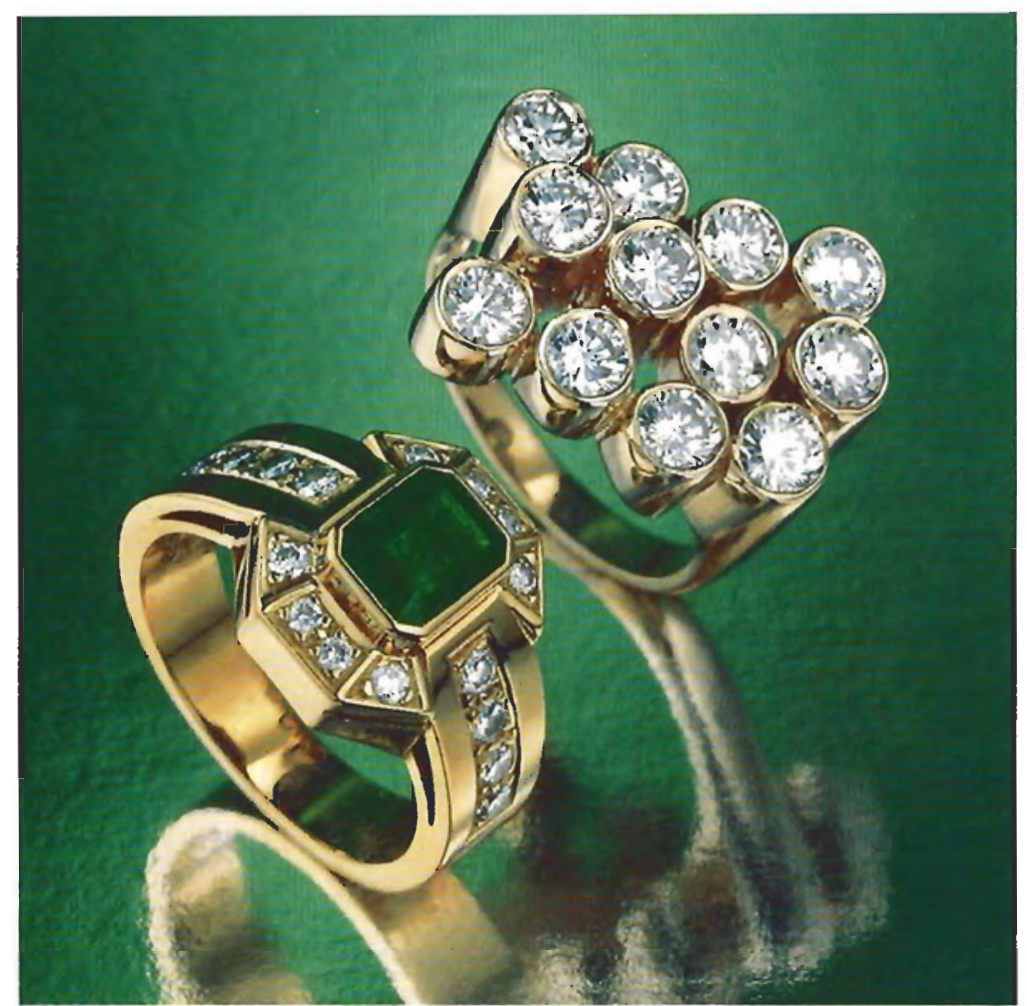

Figure 3. Bezel settings help protect the girdle and pavilion areas of any gemstone, but are particularly useful for stones that are less durable or, like the bezel-set emerald shown here, have a tendency to chip or crack. Tube setting requires more pressure in burnishing than a regular bezel setting and so is recommended only for more durable stones, such as the dianonds shown here. Emerald ring by Silverhorn, Montecito, CA; diamond ring by The Altobelli lewelers, North Hollywood, CA. Photo (c) Tino Hammid.

girdle edge is protected; however, flush setting is recommended only for durable stones because of the stress created during the setting procedure.

In this style, stones are set so that $5 \%-10 \%$ of the crown area is covered by metal with no visible means of being held in place. The stone is placed in a seat burred into the metal and then metal is burnished over and around the circumference of the stone with a punch and a chasing hammer, reciprocating hammer, or burnisher. Even stones considered durable may be damaged if the stone is accidentally struck during the setting process. Various shapes of stones may be flush set, but caution is required in the setting of sharp points.

This setting is best used for diamond and, with care, corundum. Other stones require a very delicate touch and extreme care to prevent breakage. This technique is not recommended for stones that are fragile or easily cleaved.

A gypsy mounting is a ring style with a moderate to high dome at the top of the ring in

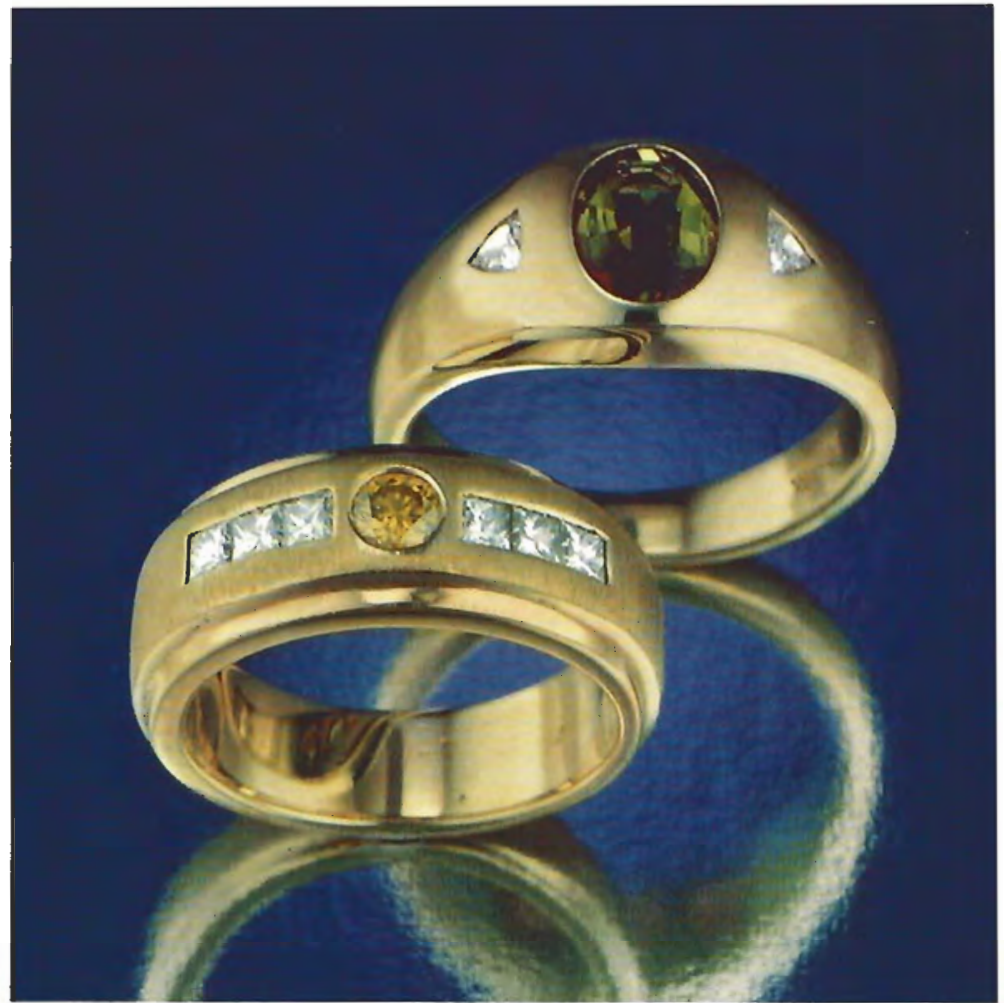

Figure 4. Although flush setting offers good protection to the girdle area, it is best used for durable stones such as the yellow and white di amonds shown here, because of the stress created during the setting process. An experienced bench jeweler, however, can set even a relatively fragile stone in this style, as evidenced here by the andalusite flush-set in a gypsy mounting. Diamond ring by Steven C. Martin, The Gold Masters, Woodland Hills, CA; andalusite ring by Krementz, New York; photo (c) Tino Hammid.

which a center stone is often flush set (again, see figure 4). The center stone and any accent stones may be enhanced further by bright cutting the metal that surrounds them.

Channel Setting. This is an excellent way to enhance ring shanks or to lead the eye to a central focal point. Channel setting provides a very clean, tailored look (figure 5) and may be accomplished with round brilliant-cut, baguette, or, quite effectively, Quadrillion (square brilliant)-cut stones. An advantage of channel setting is that the stones are set low in the mounting and are protected at the girdle.

In this method, a seat is burred between two walls of metal which form a channel. The stone is then pressed into place, first one side and then the other. This style of setting is best accomplished with durable stones such as diamond or corundum. There is a significant risk of breakage with less durable stones (depending on fractures or inclu- 
Inlay. Although not as common as the other techniques described above, inlay is used to create a visual picture of pattern. Opaque gem materials (e.g., turquoise, coral, mother-of-pearl, etc.) are most commonly used for inlay, but virtually all translucent to transparent stones (particularly opal, amethyst, and frosted rock crystal quartz) may be inlaid to produce a smooth, tailored look.

First, a metal channel or pattern of sections separated by metal walls is created. Gem materials are cut to fit these channels or sections and are then secured in place by an adhesive, usually epoxy. A related technique is intarsia (Elliott, 1986). Chips of opaque gem materials may also be used to fill pattern sections by first filling the section with colored epoxy and then fitting the chips into it. The chips are then ground off even with the metal walls and the piece is polished.

\section{General Durability Considerations in Designing} with Colored Stones. These setting styles may be used alone or in combination with one another to effectively enhance and draw attention to the stone(s)'being presented. To safeguard fragile stones, however, planning for protection is best done in the design stage.

One of the best ways to protect fragile gems is to design a mounting in which metalwork is sculpted up around the gem to at least the girdle level (figure 7). This area is often subject to chipping, as evident in figure 8 . Another method to achieve protection is to set more durable stones around the fragile gem. Be extremely careful, however, to make sure that a harder stone does not actually touch a less durable one, as this is a common cause of damage during subsequent wear (figure 9).

When using more than one stone in a design, be aware, and make your customer aware, of the risks involved with the less durable as well as the more durable gem. Diamonds and pearls, a popular combination, offer a particularly good example of the need for caution. Diamond can resist most setting, repair, and cleaning techniques, as well as most abuse during wear. Pearls are much more fragile and cannot withstand heat, polishing, or harsh cleaning solutions. Pearls strung with diamond rondels risk abrasion, while those strung with gold beads risk both abrasion and discoloration. Even a pearl enhancer can abrade or discolor the pearls and cause wear to the silk.

Many manufacturing procedures are done be-

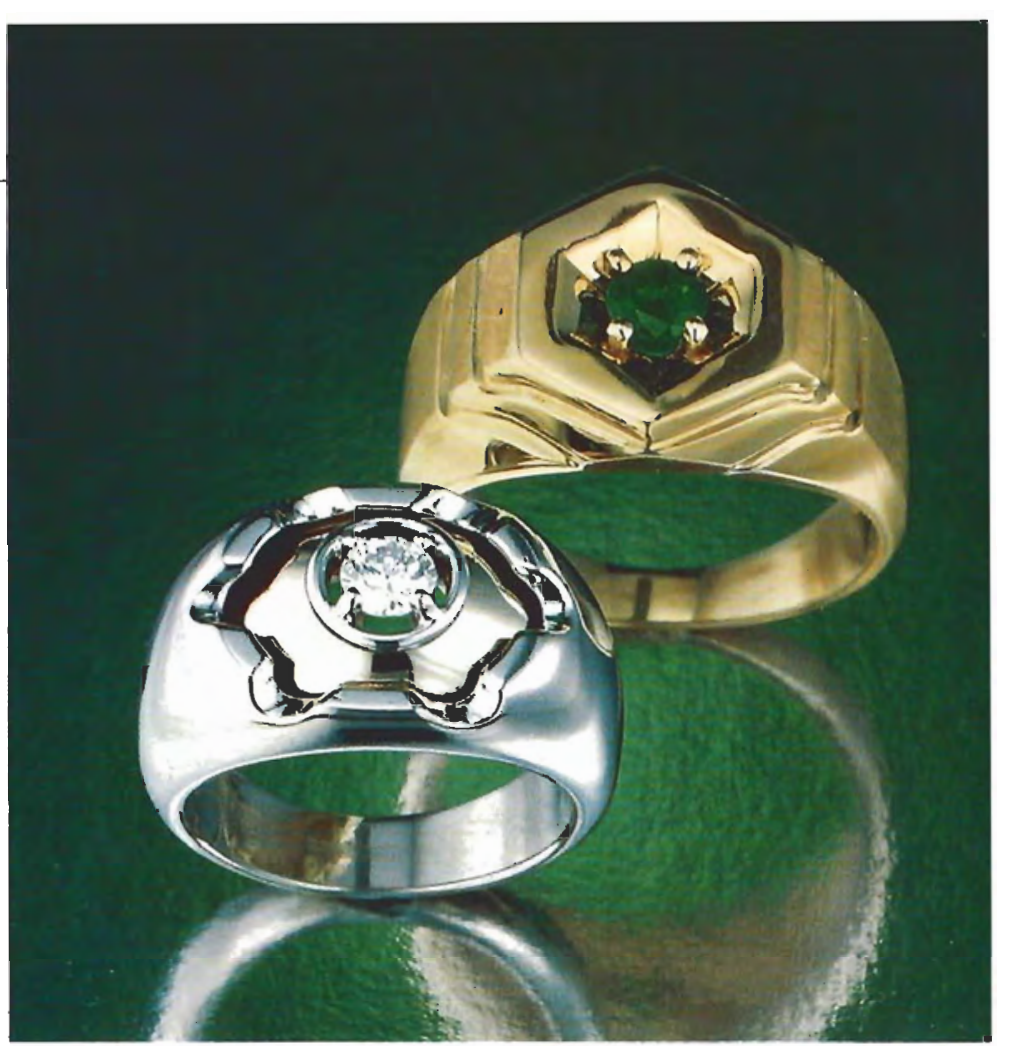

Figure 7. One way to protect a potentially fragile girdle is to design the setting so that metal surrounds this area of the stone. Diamond ring by C. Y. Sheng, GIA, Santa Monica, CA; emerald ring by The Altobelli lewelers, North Hollywood, CA; photo (C) Tino Hammid.

fore the stones are set and thus pose no threat to the gem. Most setting procedures are accomplished without the use of the torch, the potentially most dangerous of the jeweler's tools. Occasionally, though, the design of an item will require that some stones be set prior to completing the mounting. In cases such as this, the stones set first

Figure 8. Even with diamond, the girdle can be severely damaged if it is not adequately protected

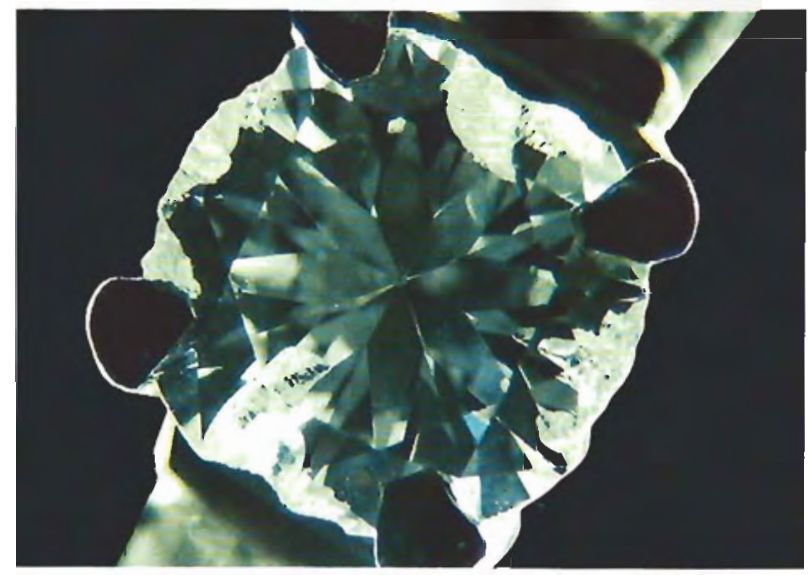




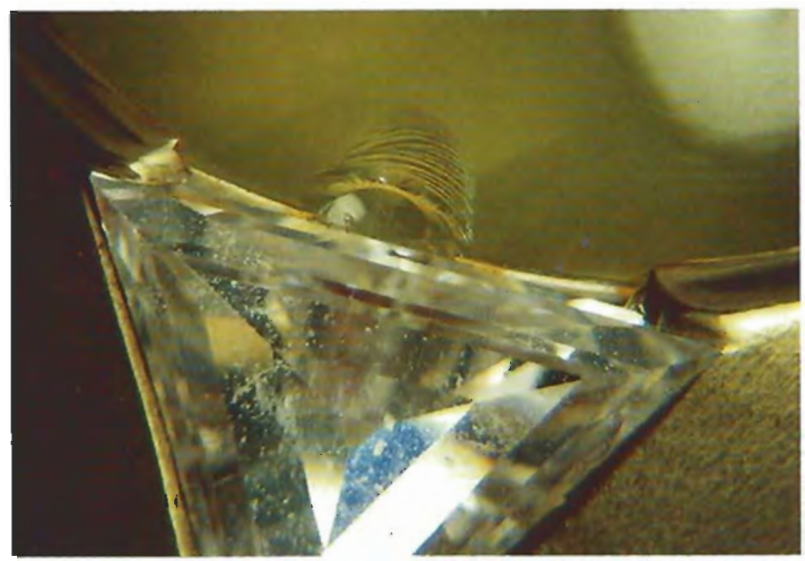

Figure 9. An improperly set diamond can chip or otherwise abrade a less durable stone, as evidenced by the diamond and chrysoberyl ring seen here.

must be able to withstand the heat of the soldering process (see chart and "Repair" section below). Because of their resistance to heat, diamonds are commonly used as accent stones in this type of setting.

\section{REPAIR}

Jobs received at the repair bench (sizing, halfshanking, retipping) can sometimes be accomplished with the stones still in the mounting if the bench jeweler is knowledgeable about the durability of the stones and the effect on them of the various tools and procedures used in repair /see chart). It is also important to take into consideration the presence of inclusions in the stone and the

Figure 10. The heat from a torch may cause inclusions in a stone to expand and ultimately fracture or break the host gem, as illustrated by the heat-damaged peridot shown here.

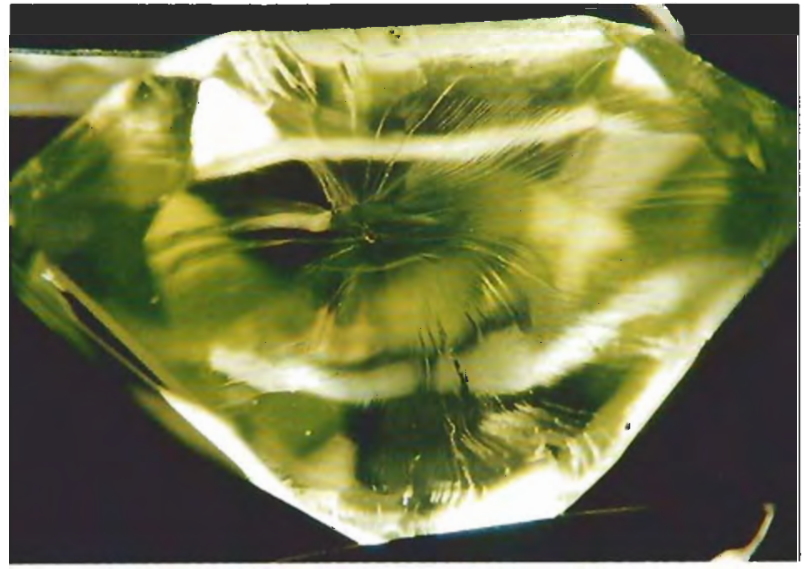

possibility that it has been enhanced in a manner that might affect its durability. Many gems (e.g., emerald, topaz, tourmaline) contain liquid inclusions that may expand and rupture when heated by the jeweler's torch, causing the stone to fracture or even break (figure 10). In the case of an irradiated yellow sapphire, which as a variety of corundum is durable, the vibrant yellow color imparted by the irradiation process fades rapidly when held close to a simple flame (Keller, 1982). A torch could not be used close to such a stone without adversely affecting the color. The pickle pot and polishing wheels should also be used with consideration to the potential damage they may cause.

Jewelry should be thoroughly cleaned before any repair procedure is begun. No repair should be attempted with the stone in place until the gem has been identified.

Jeweler's Torch. The torch is one of the jeweler's most frequently used tools. It is essential to many aspects of repair and fabrication work, from basic sizings to the intricate fabrication of wire baskets and filigree work. Whenever possible, the stone should be removed from the mounting before the repair procedure. When the item must be soldered with the stones in place, caution is critical (figure 11). There are some jobs that can be accomplished without removing the stones if the stones can

Figure 11. Use of the torch during a retipping procedure on the center diamond resulted in the permanent clouding of the surrounding peridots, which are very heat sensitive.

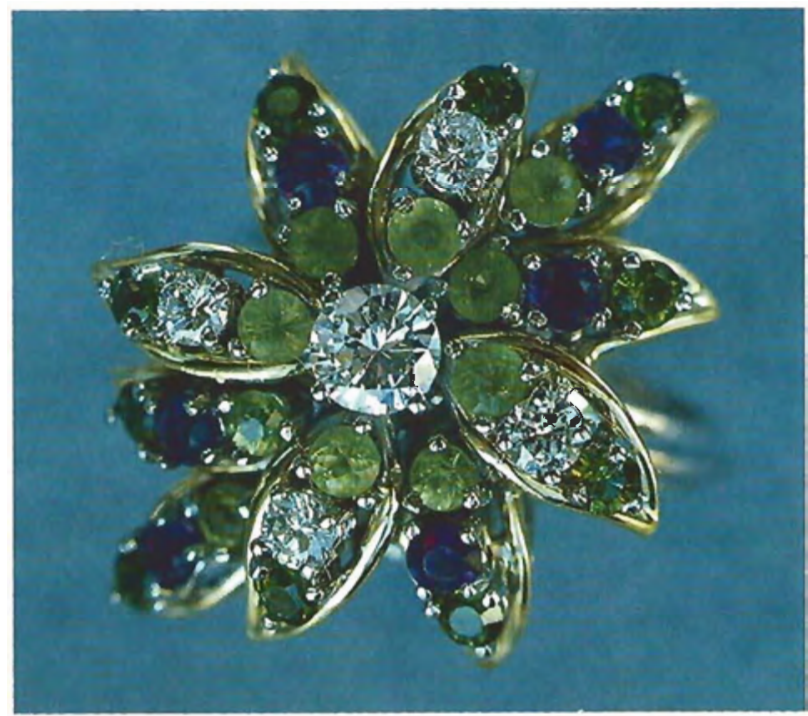




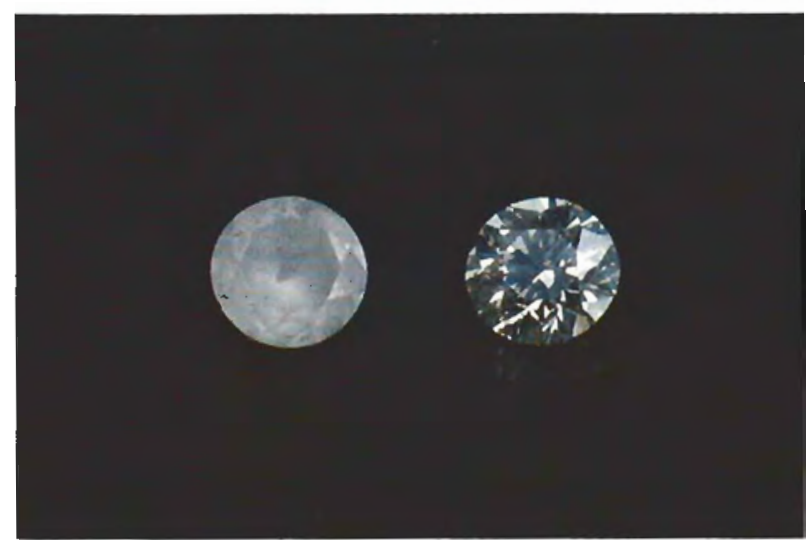

Figure 12. Improper use of the jeweler's torch caused permanent clouding and cracking of the diamond on the left, shown here with an undamaged diamond. Photo by Robert Weldon.

take heat, if no inclusions are present that could cause damage, and if no enhancement has been done that could be altered by heat. The skill of the person performing the repair and the type of torch being used are important factors in the success of soldering close to any stone.

Everi diamonds may cloud or crack under the jeweler's torch (figure 12). Clouding, which may occur when heat is applied to a dirty stone, is often permanent; since it is confined to the surface, however, it may be removed by repolishing the facets on a lap. Uneven heating may cause a diamond to cleave. Any heating procedure should be done with an even, gentle, constant motion. Keep the torch moving in a repetitive cycle across the stone and prongs being repaired / this is especially important if the stone is large). Natural green, and all colors of irradiated, diamonds may change color if heated, so remove these stones from the piece before attempting repair work (D. Moran and D.V. Manson, pers. comm., 1987).

The expansion of inclusions (such as carbon dioxide fluid inclusions; see Koivula, 1986) as well as uneven heating of the stone can cause fractures or breakage in corundum. In addition, use of a borax-containing soldering flux or pickle solution may etch the surface of corundum (figure 13). Use caution when working with star corundum. Black star sapphire can withstand heat if extreme care is used, but star ruby and other colors of star sapphire are extremely susceptible to fracture. Corundum could be inadvertently heat-treated by the torch, which might cause the color to change (R. Kane, pers. comm., 1987).

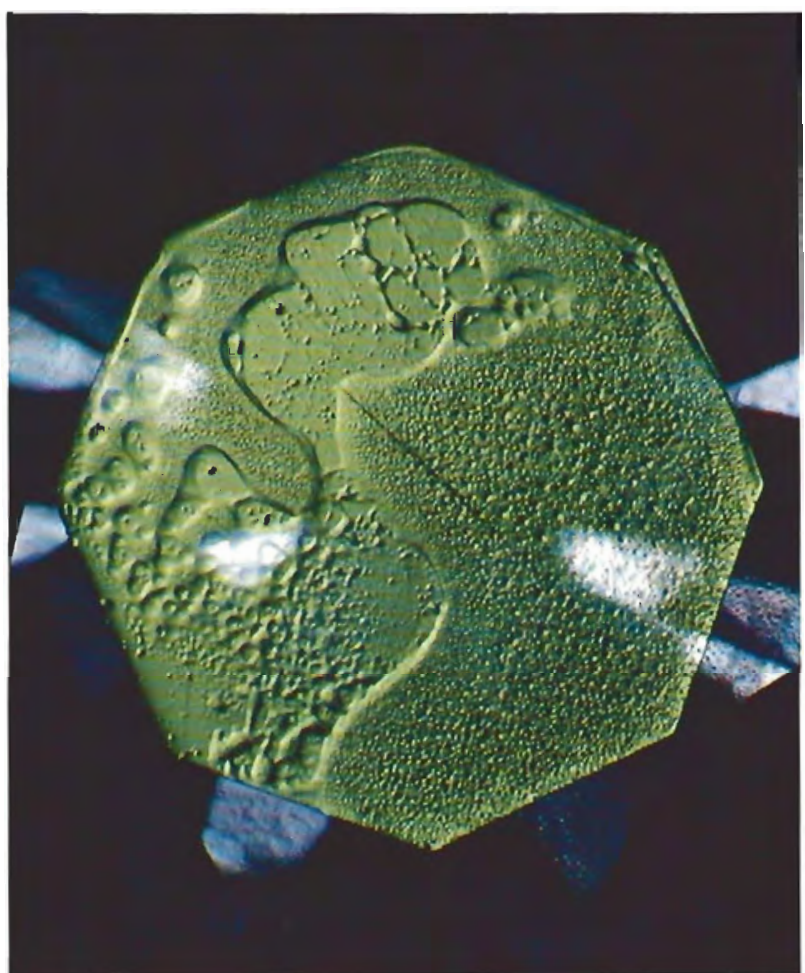

Figure 13. The use of a borax-containing soldering flux resulted in severe etching of the table of this sapphire. Photo by Robert E. Kane.

The use of the torch in conjunction with virtually all other stones is very risky; heat must be applied with extreme caution if at all and only by a qualified bench jeweler. There are, however, some techniques for protecting heat-sensitive stones when work must be done on an area away from the stone itself: (1) bury the stone in wet sand; (2) wrap the stone in florist's putty or clay for support and then submerge it in a container of water until the water level is at stone height, leaving, in the case of a ring, the shank exposed; or (3) pin the piece stone-down onto a wet sponge. Again, though, even these techniques should be attempted only by an experienced bench person.

Pickle Pot. The pickle pot usually contains a buffered sodium bisulphate solution (usually 2.2 lbs. to 1 gal. of water). This solution is used to remove surface oxides (e.g., copper oxide) created when the metal is heated during soldering or annealing.

Because pickling solutions are usually kept at a warm temperature $\left(160^{\circ} \mathrm{F} / 91^{\circ} \mathrm{C}\right)$, and warm acids adversely affect many types of stones, caution is 


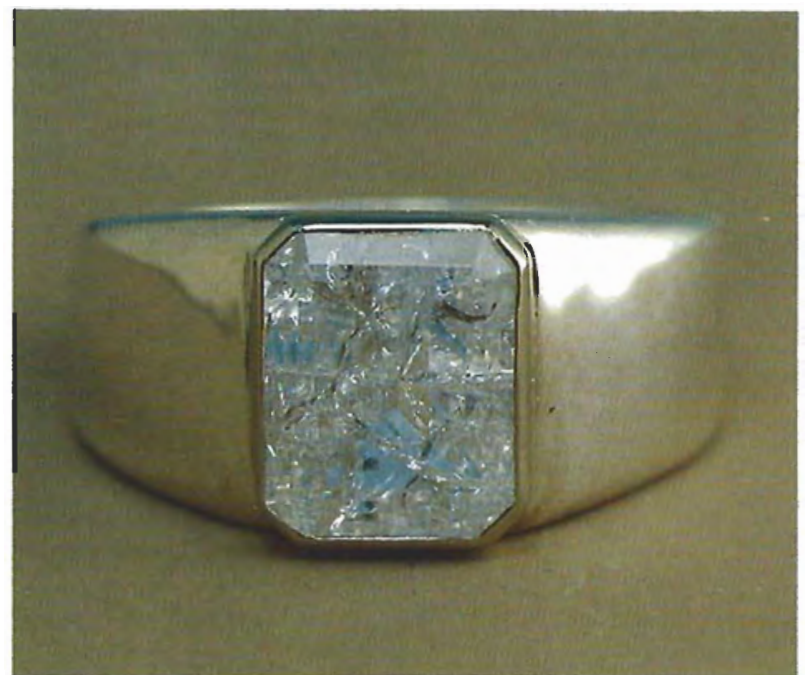

Figure 16. Even the most durable of gemstones, diamond, can be severely damaged by thermal shock.

for pearls, do not scrub the pearls forcefully, but rather brush them gently to remove surface dirt, especially, in and around the drill hole. Be sure to rinse the pearls thoroughly, since any soap residue will attract dirt. Pearls that are strung should be placed on a soft clean towel until both the pearls and the silk are completely dry (at least 24 hours). Never hang pearls to dry, as this causes the silk to stretch, weakening and possibly fraying it. Because of the possible damage to the silk caused by the washing process, the author recommends that pearls be restrung after they have been cleaned and thoroughly dried.

Many of the "dips" sold for cleaning jewelry contain ammonia and should be used with caution, if at all. Another fairly common home practice is to clean jewelry with a toothbrush and toothpaste. Again, caution is advised, as toothpaste and similar cleansers are very abrasive and will scratch soft stones. Compressed gas (canned air), used by some in the trade, may cause thermal shock if a roomtemperature stone is submitted to a blast of this supercooled gas.

Two instruments commonly used for cleaning jewelry are the ultrasonic and the steamer. The ultrasonic cleaner is effective in removing dirt and buffing compound from areas that cannot be easily cleaned with a brush (e.g., the pavilion area of a mounted stone). The steamer removes any residue from cleaning or polishing and forces residue out of intricate (e.g., filigree) or hard-to-reach areas. Used properly, these two cleaners produce excellent results on many stones, but they can be disastrous for others (see chart). Extreme caution and very limited exposure to each method are recommended, since there are risks involved in using them on any gem material. Regardless of the cleaning method used, always carefully examine the stone prior to and immediately after cleaning to check for possible damage.

Ultrasonic Cleaner. The ultrasonic works on the principle of tiny bubbles imploding against the item. These bubbles are caused by vibrations generated by high-frequency $(20-40 \mathrm{~Hz})$, highintensity sound waves that travel through the liquid. This action both scrubs exposed surfaces and produces heat that is potentially damaging to many sensitive, porous, or enhanced stones /see chart).

Ammonia and water, a solution commonly used in the ultrasonic, may damage the surface of sensitive stones as it heats up. A gentle solution, such as polishing compound remover (which does not contain ammonia), is effective for removing buffing compounds and risks less damage to the surfaces of stones (and metals) being cleaned. For cleaning jewelry, a mild liquid soap or liquid dishwashing detergent (check for ammonia content) is recommended. Caution is still required with sensitive stones.

Porous stones (e.g., turquoise, malachite, lapis lazuli) may absorb some of the cleaning solution, which could cause discoloration. Stones that have been oiled, such as emerald (and some ruby) may appear to lose color and gain inclusions as the oil is driven out of fractures (figure 17). Dyed stones may suffer a similar reaction. Pearls may have cracks beneath the surface of the nacre that can be enlarged or brought to the surface by the vibration of the ultrasonic. Other gem materials with internal fractures or cleavages run the same risk. Even stones that are normally considered safe for cleaning in the ultrasonic may be at risk if left for more than a few minutes. Extended exposure to the vibrating motion could cause the expansion of fractures or cleavages that might have been unharmed if exposed for a shorter period.

Steam Cleaner. The steamer is another useful but potentially dangerous tool. It cleans and dries jewelry by way of a compressed blast of steam. This blast forces dirt and oils away from the area where the steam is hitting the stone. Steaming often adds that "extra sparkle" to stones and 

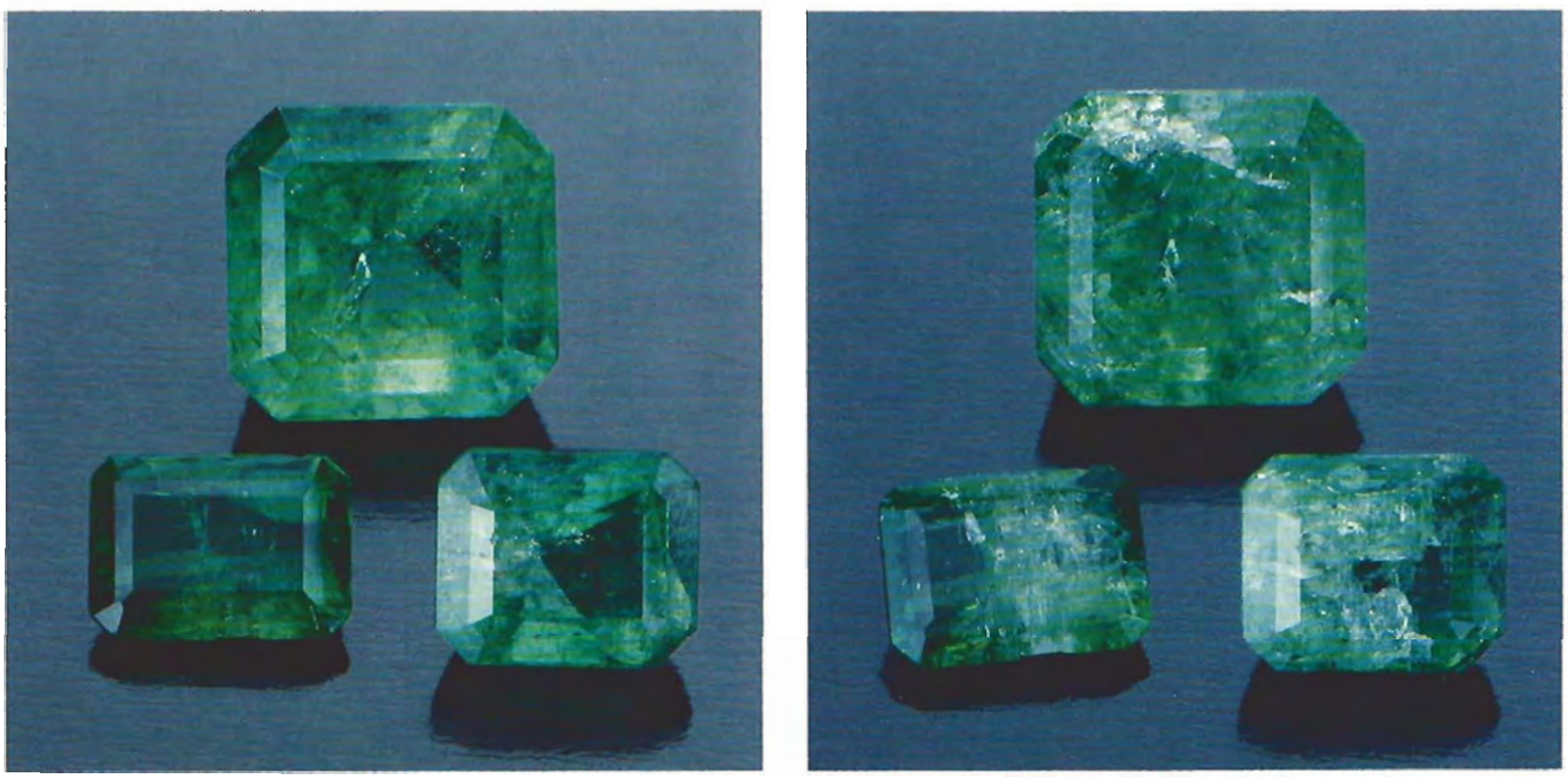

Figure 17. Most emeralds in the trade today are oiled (left). Their appearance may be altered radically (right) when the oil is driven out of the fractures by a procedure such as cleaning in an ultrasonic. Photos (c) Tino Hammid.

removes any residue from ultrasonic cleaning. Although the steamer may force dirt into fractures (figure 18) or inclusions that break the surface of a stone that is not relatively clean to begin with, the greatest potential danger of steaming is thermal shock.

Introducing the change in temperature gradually is very important. It is best to hold the jewelry item securely by its mounting with plastic-coated tweezers (the coating prevents scratching and slipping). Begin the temperature change by running warm, then hot, water over the stone, and then begin steaming by holding the item in the outer fringes of the steam. Gradually lift the piece in to the blast of steam /this allows time for an even temperature change). Once the stone is acclimated, short, frequent blasts of steam work best during the cleaning process. However, care should be taken to steam large stones evenly, as an isolated blast of steam on a small section will cause that area to heat up and expand faster than the rest of the stone, resulting in fracture.

Occasionally, steam cleaning will leave a film or the stone-set item will still appear dirty; of ten it is then put back into the ultrasonic or directly into running water. This can be a costly mistake, because the process of steaming heats up the stone considerably (steam temperature is approximately $300^{\circ} \mathrm{F} / 149^{\circ} \mathrm{C}$ at $67 \mathrm{psi}$ ) and the lower temperature may cause thermal shock and shatter the stone. To minimize the risk, always allow a steamed stone to cool for a few minutes before any further cleaning is attempted.

Boiling. This procedure is not recommended for any stones other than diamond. Even then it should be used only with extreme caution, since inclusions in the diamond could be adversely affected by the heat. If you feel you must boil a diamond, the safest procedure is to place the stone

Figure 18. This star sapphire was stained when dirt was forced into the fractures during steam cleaning.

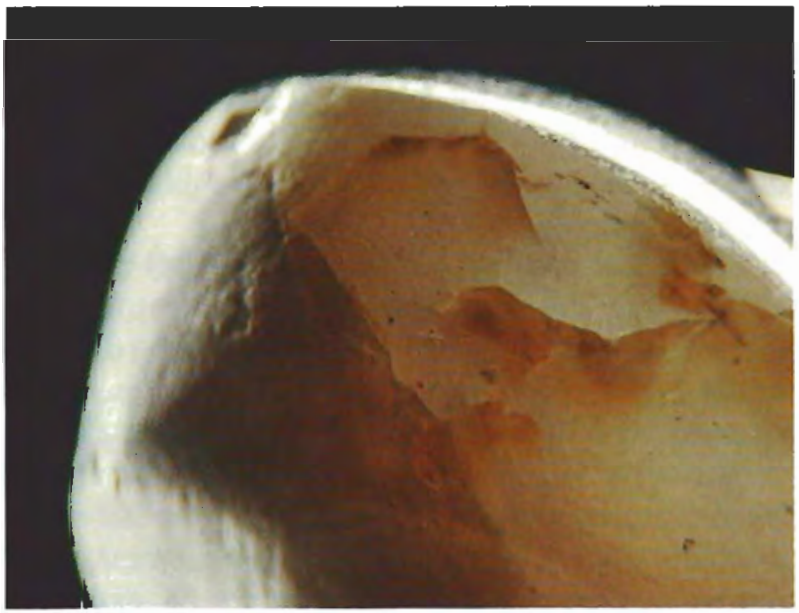


in cold water and gradually bring the water to a boil. Never put the stone directly into boiling water. Allow the stone to cool thoroughly after boiling before any further work is done.

\section{DISPLAY}

Display plays a significant role in the sale of jewelry. Attractive display cases highlighting unusual loose stones and/or unique pieces capture the attention of potential customers.

Again, gemstone durability (specifically, stability) is important in determining how and where some items can be shown to best advantage. Several stones are sensitive to both heat and light (see chart). For example, opals are subject to dehydration, which may result in cracking and crazing. Consequently, opals are best displayed in inside cases away from the case lights and direct sunlight, both of which can generate considerable heat.

Stones that fade easily in light (e.g., most kunzite) should not be displayed in windows exposed to sunlight or in brightly lit cases. Some amethyst,t, too, is subject to fading when exposed to strong, direct light for a long period.

\section{CARE TIPS}

Professionals should be as concerned with the care of the stone after it is sold as they are while it is in their possession. Consequently, any durability problems that affect decisions with regard to setting, repair, cleaning, and display should be communicated to the purchaser in the form of care tips.

Pearls and opals are two of the better-known gems that benefit from special care. Both are subject to dehydration and are best stored away from prolonged exposure to heat. Pearls should also be protected from damaging chemicals that might attack the nacre and from rough-textured fabrics that might abrade the nacre. Make-up (which may cause discoloration), perfume (which may attack the nacre), and hair spray (which may coat the pearls and lead to dehydration) should always be applied and allowed to dry before the pearls are put on. Pearls should not be worn next to the skin if acidic perspiration is a problem. They are best stored in a soft silk pouch rather than loose in a jewelry box, where they risk abrasion.

Opals are fragile stones, easily scratched, broken, or chipped. Care should be taken during wear that the opal does not receive any sharp blows, and opals should be stored away from other stones or settings that might cause abrasion. Contrary to popular belief, soaking opals in mineral oil does not prevent cracking or crazing; it only temporarily masks existing cracks, which again become readily visible when the oil dries out.

Jewelers should advise customers who purchase a potentially light-sensitive stone (e.g., kunzite, amethyst, etc.) that it is best used for evening or occasional wear and that it should be kept out of light when it is not being worn.

\section{CONCLUSION}

Gemstones are rare products of nature and have been revered for their beauty and durability for thousands of years. Much has been learned about the commerce and culture of earlier peoples from the gems and jewelry articles found in ancient ruins. Properly cared for, most gemstones should retain their beauty for hundreds, if not thousands, of years. In fact, turquoise and lapis lazuli are constituents in one of the oldest known pieces of wrought jewelry, which dates back more than 5,000 years (Vilimkova, 1969). When one considers the history that accompanies gemstones, and the significance to future generations that our creations might have, it seems only right that we do our best to preserve the gems we wear. One of the easiest ways to do this is to understand the areas where each individual gemstone needs special consideration and to compensate through our design processes, manufacturing techniques, and care procedures.

\section{REFERENCES}

Elliott I. (1986) Contemporary intarsia: The Medvedev approach to gem inlay. Gems \& Gemology, Vol. 22, No. 4, pp. $229-234$.

Kane R.E. (1984) Natural rubies with glass-filled cavities. Gems e) Gemology, Vol. 20, No. 4, po. 187-199.

Keller P.C. (1982) The Chanthaburi-trat gem field, Thailand. Gems e) Gemology, Vol. 18, No. 4, pp. 186-196.

Koivula J.1. (1986) Carbon dioxide fluid inclusions as proof of natural-colored corundum. Gems as Gemology, Vol. 22, No. 3, pp. 152-155.

Nassau K. (1984) Gemstone Enhancement. Butterworth \& Co., London.

Nassau K., Kane R.E. (1983) Treated gens: What, when, how and why (chart). Jewelers' Circular-Keystone, Vol. 154, No. 5 , pp. 42-47.

Palache C., Berman H., Frondel C. (1944) The System of Mineralogy of James Dwight Dana and Edward Salisbury Dana, Yale University 1837-1892. John Wiley \& Sons, New York.

Sinkankas J. (1972) Gemstone \&ineral Data Book. Winchester Press, New York.

Vilimková M. (1969) Egyptian Jewelry. Paul Hamlyn, London. Webster R. (1983) Gems, 4 th ed. Butterworth \& Co., London. 